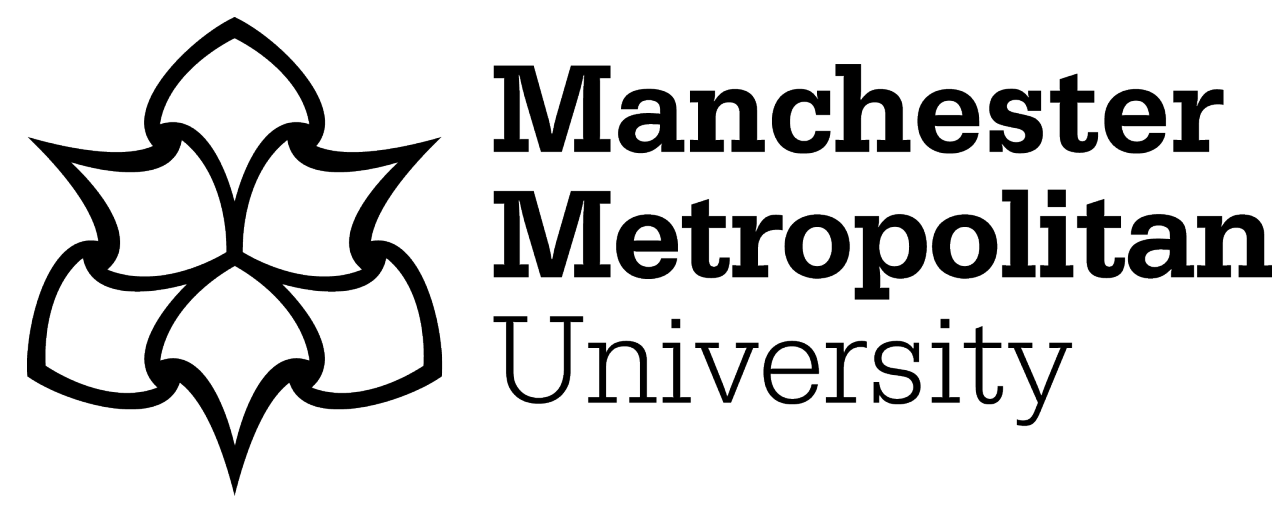

Wimpenny, K, Knowles, RV, Ramsay, C and Speculand, J (2019) \#3CityLink: Disrupting Learning through a Translocal Art Pedagogy Exchange Project. International Journal of Art and Design Education, 38 (2). pp. 328-343. ISSN 1476-8062

Downloaded from: https://e-space.mmu.ac.uk/624346/

Version: Accepted Version

Publisher: Wiley

DOI: https://doi.org/10.1111/jade.12193

Please cite the published version 


\title{
\#3CityLink: Disrupting Learning through a Translocal Art Pedagogy Exchange Project
}

\section{Katherine Wimpenny, Rachelle Viader Knowles, Christine Ramsay and Jacqui Speculand}

\begin{abstract}
\#3CityLink involved fine arts researchers, artists and students in three cities: Regina, Canada; Coventry, UK; and Gyumri, Armenia. The project presented a platform for translocal creative interactions using online screen-based media and on-the-ground dialogues. Artists and students investigated the concerns of their locale, questioning the role of the artist in building narratives, revealing lost histories and imagining the future of where they live. Using descriptive case study design, the findings present the opportunities for enriching the student learning experience through challenging habitual approaches to art production, through alternative approaches to digital pedagogy in art education. Students' artwork took on new dimensions beyond what they could have produced working in relative isolation in a university-only studio setting. Students were encouraged to pursue and persist in online learning spaces whilst also taking responsibility for organising their own learning and that of others. Nonetheless, using visual technology and social media for connected, artistic, co-investigation needs further refinement to engage learners, and enhance the quality of visual presence and its potential in open education.
\end{abstract}

\section{Keywords}

art education, translocality, dialogue, digital pedagogy, social media, collaboration, learning spaces, uncertainty

\section{Introduction}

\#3CityLink presents an online, translocated (approaching the concept of global through local-to-local) co-learning, artistic project, linking three cities with complex histories. Regina, Canada is a place struggling with the legacy of colonisation and 
Canada's cultural genocide of Indigenous people; Coventry, UK is officially designated an International City of Peace and Reconciliation related to its devastation in the Second World War; and Gyumri, Armenia is a city recovering from the legacies of war, genocide and natural disaster. As Station 2 of the larger Regina-based durational series of exhibitions and events, Meet in the Middle: Stations of Migration and Memory between Art and Film (2014-2017), the aim of \#3CityLink was to create a context where new forms of translocal dialogues could emerge between art and film across countries, galleries, screens, social technologies and learners. As educators and researchers involved in the project, from the UK, Canada and Armenia, the project team were interested to explore how students and staff responded to the shifting of the creative space in the context of cross-cultural encounters.

Oblinger $(2006,11)$ identifies the power of 'built pedagogy' - the impact of the environment on teaching - to meet the learning styles of today's students and its focus on the global, the experiential, the interactive and the social. \#3CityLink offered two main opportunities to facilitate built pedagogy: (1) Disrupting fine art, fine art $\&$ illustration and film production students from their natural (separate) studio habitats by extending the classroom into an open, public gallery space; and (2) Enabling students to collaborate with learners in two other locations, thus creating a translocated co-learning space through shared teaching and use of social media around a common theme. The research questions were: how can online screen-based media and on-the-ground dialogue encourage a translocated co-learning and co-teaching experience for students to investigate the role of the artist in rebuilding narratives of where they live? How would digital media interact with learning environments and educational culture? And, what impact would the learning experience have on students' developing art practice and disciplinary understandings? Using a descriptive case study approach, the project team explore, through the sharing of both staff and student reflections, how online screen-based media and on-the-ground dialogue encouraged a translocated, co-learning experience.

\section{Theoretical contexts}

\section{Learning spaces}

Dugdale (2009) describes the learning landscape as a diverse setting of approaches from specialised to multi-purpose, formal to informal, and physical to virtual, arguing that future learning spaces will be designed around patterns of human interaction, not disciplines and technologies. This may in time lead to more generic use of spaces for teaching, with, for example, the evolution of the fine art studio into a more general space for teaching and learning. Jamieson et al. (2000, 223), discuss the design of learning spaces and the hierarchies created by the separation of staff and student spaces, arguing that this structure creates power relations and undermines the development of 'collaborative learning communities'. They suggest a more user-centred approach that is focused on the purpose of the learning activity and student ownership of learning spaces.

Educators have to engage more with the world in which students live, and strive to integrate technologies and tasks that are meaningful. McLoughlin \& Lee (2008) describe the use of social media software to engage students with a wider community and enable collaboration outside the physical walls of the institution. 


\section{Art, education and research}

Approaches to fine art education continue to challenge the primacy of the studioteaching model, or blur the distinction between 'art' and 'education', the so-called educational turn in art. Bishop (2012, 241) addresses this turn in art in asking 'How can you bring a classroom to life as though it were a work of art?'. If dialogue can be accepted as a method of art, and the art produced by students is undertaken in a dialogue-based environment (the classroom), and if the categories of 'student', 'teacher', 'artist' and 'viewer' are disrupted and destabilised by the possibilities proposed by participatory practices, then as Bishop contends, 'the history of participatory art ... incites us to think of these categories more elastically'.

Further elasticity was applied to the categories of research that \#3CityLink enabled, with the project understood as both the subject of research (research about art/education) and as the art/education that led research (research through art/education) (Frayling 1993/4, 5). The practitioners and researchers leading the project undertook 'research' from differing disciplinary perspectives and contexts that brought complexity to evaluating the project. The project was understood as simultaneously art practice-based research, art education research (the focus of this article) and a collaborative artwork with all the students across the three countries sharing authorship of the work.

\section{Translocalisation of the curriculum}

Trans VSI Connection NSCAD-NETCO (1969) (hereafter Trans VSI) is an early example of an artwork-cum-pedagogical project exploring the use of communications technologies to create dialogue-based art, which unfolded between students at the Nova Scotia College of Art and Design (NSCAD) in Canada and conceptual artist lain Baxter's N. E. Thing Co. Ltd. (NETCO). The dialogue, structured as a series of instructions and responses, was performed via telex, telecopy and telephone, resulting in 'VSI' (Visually Sensitive Information), the term used within Baxter's alternative conceptual lexicon for 'art'. NETCO issued electronic propositions and the students responded with collaborative activity - photographic images, texts and drawings - transmitted back to NETCO, then exhibited at NSCAD's Gallery in Halifax, and published in book format the following year.

Trans VSI can be seen as a direct precursor to the online exchange activities that many universities now encourage. Yet, how might we relocate what once was marginal to a more central place in fine art education? Internationalising the curriculum is a feature of the portfolios of most higher education institutions, promoting student and staff mobility, and the use of digital technologies for globally networked learning (Redden 2014). Whilst the use of technology to enable virtual exchanges and collaborative assignments between geographically distant classrooms is not new, efforts are increasing to scale up these kinds of activities. In productively re-mapping corporate agendas into fine art education, \#3CityLink proposed translocalisation of the curriculum as a counter-narrative to globalisation, where connectivity, dialogue, the struggle with difference, engagement with the conditions and situations on the ground, and the acknowledgement that mobility is restricted for much of the population, are essential ingredients. Kwon's (2002, 46) critique of the 'itinerant' artist projecting art-career success through global mobility remains as relevant as ever, suggesting the ongoing need for students to encounter models that disrupt global versus local narratives. Approaching 'the global' through the concept of the translocal, asserts and introduces fine art students to, 
a critical perspective on the globalised and networked society that our 'global graduates' will enter, a society increasingly polarised between the grounded many and the mobile few (Bauman 1998, 72).

\section{Project design}

\#3CityLink was a three-phase translocal collaborative project linking fine arts researchers, artists and students in three cities - Regina, Coventry and Gyumri to create a context where new forms of translocal dialogues could emerge. Concerned with issues of peaceability and citizenship, the project presented a platform for translocal creative interactions using online media and on-the-ground dialogues. In the initial two-week 'research phase', artists and students in each city investigated the current concerns of their locale as a place of large-scale historical trauma, and questioned the role of the artist in building narratives, revealing lost histories and imagining the future of where they live. Suggested themes included cityscapes, archaeologies, architecture, city planning, transit, and communications. During the 'live phase', the three groups used Skype to connect in their respective gallery spaces over two weeks (6-14 November 2014) for two hours each day, working together to find (or not) these common links, build intercultural connections and create a collaborative installation artwork in three gallery spaces. Outside this shared time, social media was used to connect the students and staff. Facebook and Twitter were identified as the most popular and accessible platforms for dialogue.

The gallery spaces in each city (Lanchester in the UK, 5th Parallel in Canada, and Berlin Art Hotel in Armenia) hosted students' work as they created an unfolding dialogue of images, sounds, videos, physical structures, objects and stories in response to the question of how artists can shift the narratives of their cities beyond histories of unhealed trauma, towards linked, creative futures. Together, students worked to transform each local space into an imagined translocal place drawing from elements of each of the three cities (see Figure 1). A library area in each gallery featured research materials from each location, such as maps, newspapers and catalogues, giving contextual insight.

In the final 'outcomes' phase, the project shifted from student-facing to research-focused. Five of the participating researchers reflected on the project for a suite of linked papers delivered at the Arts in Society Conference (Imperial College London, July 2016), in response to the special conference theme 'The Work of Art in the Age of Networked Society'. The outcomes of the project are consolidated in this article as the concluding international dissemination element of \#3CityLink.

\section{Methodology and methods}

Descriptive case study methodology was used to develop a detailed account of the subject of study and greater understanding of 'the case' (Simons 2009) as a 'specific, complex, functioning thing' (Stake 1995, 2). In \#3CityLink, the focus was in understanding students' perspectives about their learning experience, and how online screen-based media and on-the-ground dialogue could encourage a translocated, co-learning experience. 


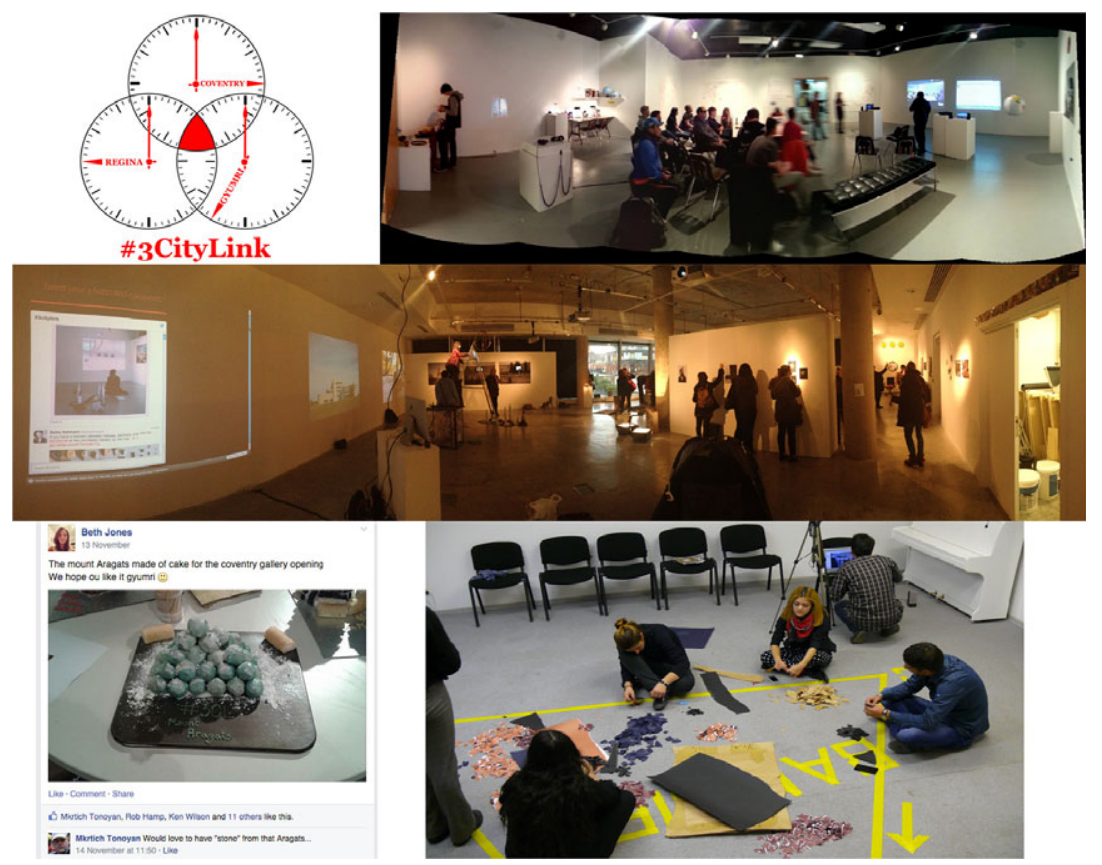

\section{Figure 1}

Photographs of the students preparing their artwork for the live gallery space. Clockwise from top right: 5th Parallel Gallery, Regina; Lanchester Gallery, Coventry; Berlin Art Hotel, Gyumri; Lanchester Gallery, Coventry; \#3CityLink logo

The methodology was social constructionist, in that, whilst individuals are seen as engaging in their world and making sense of it, individuals' perspectives and experiences are viewed in the context of history, social perspective and the political sphere (Gergen 2003). Students' development of their art practice in the context of space, place and others, was viewed as the case, with differences in institutional, student and societal demographics between the British, Armenian and Canadian contexts taken into account.

\section{Project participants}

The project was housed as part of the course delivery of the respective programmes of study across the three institutions. Table 1 identifies the staff and students involved at each institution. The project received ethical approval from Coventry University (P28805/6.11.15).

\section{Data collection}

All students and staff members were invited to share their perspectives about the experience of taking part in the project. These perspectives were accessed using online and face-to-face methods (see Table 2). For example, student data were captured from the discussion threads on Twitter and Facebook, email contact by the research team, Skype interviews, and three module evaluation and feedback sessions at Coventry University (one directly following the module, another one month after the project end date, and a final session six months after the module ended) (see Figure 2). 
TABLE 1 Study participants

\begin{tabular}{lllll} 
Institution & Course & Level of study & $\begin{array}{c}\text { Numbers of } \\
\text { students }\end{array}$ & $\begin{array}{c}\text { Numbers of } \\
\text { staff involved }\end{array}$ \\
\hline Coventry University & $\begin{array}{c}\text { Fine Art, Fine Art } \\
\text { \& Illustration }\end{array}$ & Level 1 and 2 & 103 & 5 \\
\hline University of Regina & $\begin{array}{l}\text { Film Production,Visual Arts, } \\
\text { Creative Technologies }\end{array}$ & Level 2, 3 and 4 & 50 & 5 \\
\hline Gyumri Academy & Fine Art & Level 3 and 4 & 13 & 2 \\
\hline
\end{tabular}

TABLE 2 Data collected from study participants

\begin{tabular}{|c|c|c|c|c|c|}
\hline \multicolumn{6}{|l|}{ Data Collected } \\
\hline Institution & $\begin{array}{l}\text { Student social } \\
\text { media (discussion } \\
\text { threads Twitter } \\
\text { and Facebook) }\end{array}$ & $\begin{array}{l}\text { Staff email } \\
\text { responses }\end{array}$ & $\begin{array}{l}\text { Skype } \\
\text { interviews }\end{array}$ & $\begin{array}{l}\text { Module } \\
\text { evaluation }\end{array}$ & $\begin{array}{l}\text { Student } \\
\text { focus groups }\end{array}$ \\
\hline Coventry University & $\mathrm{x}$ & $x$ & & $x$ & $x$ \\
\hline University of Regina & $x$ & $x$ & $x$ & $x$ & \\
\hline Gyumri Academy & $\mathrm{x}$ & $x$ & $\mathrm{x}$ & & \\
\hline
\end{tabular}
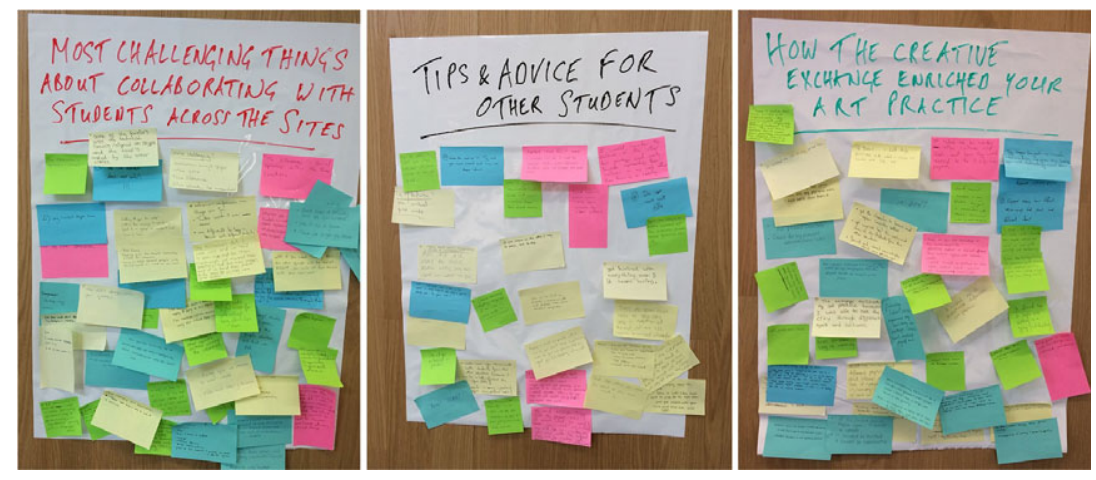

\section{Figure 2}

Billboards reflecting student feedback, Coventry University

Questions included:

- How did this creative exchange enrich your art practice?

- What was most challenging about communicating and collaborating with students across the three sites (language barriers aside)?

- If you were doing this all over again, what would you do differently?

- What tips and advice would you give to other students participating in a similar project in the future? 


\section{Analysis}

The data were transcribed verbatim and analysed collaboratively by the first and second authors using thematic analysis (Braun \& Clarke 2006). Analysis focused on how the data sets revealed student and staff perspectives about the translocal learning experience as well as their consideration of developing artistic practices. The analytic process progressed from description (where the data from students across the three institutions were organised to show patterns in content and summarised) to interpretation (where themes were developed, illustrating the significance of the patterns and their broader meanings and implications). This required an iterative process of reading, rereading, preliminary coding and generation of themes and their subthemes. The researchers kept reflective notes, highlighting connections and differences between the themes and their subthemes. Themes were defined and contextualised with data evidence.

\section{Trustworthiness}

Researcher reflexivity, peer evaluation, maintaining data integrity and being explicit about researcher stance and the research methods employed were key strategies used to maintain trustworthiness. This included awareness about the collision of different contexts, not only in terms of different approaches to research at play due to the projects teams' cultural and disciplinary perspectives, but also the socio-political agendas of the faculties and education centres to which the academic and research staff belonged, and the requirement, of course, to provide an education outcome for the students. Reflexivity was shared during the project through dialogue, and has continued in ongoing collaborations, not least in how \#3CityLink has served as a catalyst in promoting changed perspectives in each of the team members' pedagogical and research practices.

\section{Findings}

The findings from the students' and staff perspectives are presented in four overarching themes:

- Evolving art practice; translocal thinking

- Gallery versus studio: dialogue versus object

- Opening up the classroom; creativity and collaboration through social media

- Changing mind-sets about fine art education and practice

\section{Evolving art practice; translocal thinking}

There was a range of perspectives about the impact of the international learning opportunity. Some students felt that they had learnt new skills through 'Being stretched to think about how different peoples' cultural approaches to art could be so different' and 'how ideas around one subject area could be explored through so many different ideas and forms of media' (Regina).

Some students commented on the project pushing them out of their comfort zone, inspiring them to work with the ideas and techniques of others, exposing them to new practices and new artists: 'I came to realise how easily, quickly and inexpensively I can communicate with artists from completely different cultures to my own. This will leave options much more open and varied for my future practice whatever 
that may be' (Coventry). And, 'The exchange enriched my art practice because I was able to see my own city through different eyes and cultures' (Regina).

Students from across the three sites stretched one another's ideas by looking with renewed interest at their own locale. Students appreciated the benefits of shared translocal learning with the artists involved, and the ideas generated through cultural openings and cross-site communication channels. Similar to Held et al's (1999) concept of globalised learning as a continuum of the local, national and regional, \#3CityLink placed students in a spatial-temporal process, linking together human creativity across regions and continents.

The project process created openings for students to focus on other aspects of the art process not directly related to what they wanted to explore in their own artwork. Whilst the students did not all appreciate the immediate benefit of this, it was evident from a significant number of post-project reflections that shifts in the students' art practice had occurred: 'This creative exchange enhanced my ideas for my new project, however the project itself made me struggle with ideas' (Gyumri); 'When I moved into my own personal work I had extra ideas from it' (Coventry).

The collaborative nature of the project challenged students' conceptions of their art making. The co-creative aspects, where students were not merely researching ideas for their own insular work, created disruption. This included how students were able to see the outcomes of their work as a collaborative piece of art, as the following theme illustrates.

\section{Gallery versus studio: dialogue versus object}

Students were encouraged to consider their art making as a collaborative process or journey with a story, rather than an individual exercise in artistic production toward finished pieces. Students were less familiar with the concept of pieces being dynamic in the sense of moving through one creative phase to the next and being, in essence, unfinished individually, but complete as a work of art as a whole. Because of this initial focus on the product rather than the process, a number of students commented that they were 'forced to present incomplete work and were not clear why this was acceptable' and 'felt really restricted with what I could and could not do.' (Coventry)

A lack of understanding that the process can be as important as the work resulted in some students feeling that the process of creation was forced and rushed, with insufficient time to 'complete the work before the gallery exhibition went live'. Students' perceptions of what should and should not go into an exhibition was influenced by their own past experiences. It was evident some students were influenced by how the media depicts art as a finished product rather than seeing their creativity as a work in progress.

This aspect of incompleteness arguably links to Barnett's (2010) ideas on 'lifewide learning' and the role of education in contributing to the enhancement of students' active, engagement as thinking persons. Indeed, a central aim of the project was to disrupt students' mind-sets about process versus finished product, and, individual focus versus learning through creative collaboration, critique and dialogue with peers. It was evident that as the project progressed, students helped one another in the process of working together towards a common goal without feeling as competitive. Further, there was a sense of community in the galleries but relative to the size of the student body and the different schedules at each institution. Some students created work in the studio, then dismantled it and transported it to the gallery; some worked in the gallery spaces full time; and others moved 
between workspaces. Some 103 students in Coventry and 50 students in Regina participated in both group and individual projects. In Gyumri, 13 students worked closely together with two lead artists on five collaborative projects.

\section{Opening up the classroom; creativity and collaboration through social media}

\#3CityLink required students to not only work with other students across the three cities, located in three different countries, but to engage with professional artists and the wider general public, made possible through the concept of the 'open class', and made accessible through use of live feeds and Twitter hashtags. The selection of technology chosen impacted the means by which creativity and dialogue was facilitated, posing a spectrum of opportunities and unique challenges.

Facebook, Twitter and Skype were used as conduits for communication amongst the students and staff. Whilst the Coventry University staff had previous experience of using Twitter and Facebook in their teaching, Skype had not been used before, and the University of Regina and Gyumri Academy staff were new to using telecommunications technology in teaching.

The three locations were live-linked together for two hours each day using webcams in the gallery spaces. Feedback from some students suggested that although the key intention was an international art project, the reality of the dayto-day running of discussions, researching their art practice and bringing students together to work, was not always as effective as it could have been: 'Collaboration was hampered at times as people did not respond to our requests, which really slowed down the process of work being made...' (Coventry). However, for others, the creative opportunity to share international perspectives and practices encouraged students' creative engagement: 'Processing the differences in social opinions within the three locations as each city was different, created different ideas amongst the students' (Regina).

Staff also indicated that whilst some students responded well, others did not. Some of the students, who were expected to engage with the process and the project the most, did so the least. There was, however, evidence of strong students, who came into the course with a reputation for being highly motivated and more mature in their artistic vision, predictably engaging the most. In Regina, two students who had previously worked in single-channel video production gained a passion for video installation as a result of this project. In Coventry, the facilitation of discussion between first and second year students led to several instances of collaborative project work.

What was learnt from the use of different technology was that whilst students were live-linked across the sites via a video feed, consideration regarding camera set up for Skype was required. For example, the students needed to be able to both 'hear and see them' (the other students) (Coventry), to experience the installations to full effect at the other two sites, which at times proved to be challenging: 'It was hard sharing visions of work without being able to show it' (Gyumri).

Staff indicated that sound quality at times, and fixed-point webcam locations, impacted upon communication, and that the whole room needed to be viewable, not just the speaker. Some students felt inhibited by language issues, which limited the level of discussion to only simple ideas. Yet, for other students the experience of social media was very useful and experienced as stress-free: 'The web camera conference via Skype was fun; Twitter made it even easier' (Regina); 'I really enjoyed sharing ideas through social media and creating a digital exhibition. Two weeks in the gallery was also an awesome experience' (Coventry). 
Although some students commented that interest generation using social media (e.g. Twitter) was not fully utilised, the actual activity and traffic on social media was striking. Twitter was significantly less popular than Facebook: the Twitter hashtag was used in 71 tweets and the project (\#3CityLink) had 49 followers; the Facebook group had 518 members and was demonstrably more active with both text posts and images. The Twitter feed shows tweets from students and staff on the project although less external engagement (although interest from a public audience was more evident in the physical gallery spaces). The Facebook group was primarily populated with staff and students (see Figure 3), with a high number of posts during the actual contact period, but with fewer ongoing posts after the project finished. Whilst there was limited evidence on the group chat of social interaction or contact, this could have been happening in private spaces.

The project required staff to apply and use the technology they already had within the department. In the Gyumri Academy, the students were located off-campus without any dedicated technical support and basic audio-visual tools, but the students and staff found ways to communicate and work around obstacles. At the University of Regina, a dedicated graduate research assistant, with a strong background in film and social media, helped make the technology virtually flawless.

\section{Changing mind-sets about fine art education and practice}

It was evident \#3CityLink had noticeable impact upon students' art practice, including what they wanted to go on to do, as well as confirming things about themselves they wanted to change. Comments included: 'I wouldn't do painting; I'd do a big different other project; maybe a video or sculpture and do more experimentation' (Gyumri); 'I would be more inclined to use the social media aspect to collect broader or more precise ideas and then better quality of work would be guaranteed!' (Regina); 'I'd improve my communication; talk to other students from the other countries; post more photos of my work; be better organised' (Coventry);

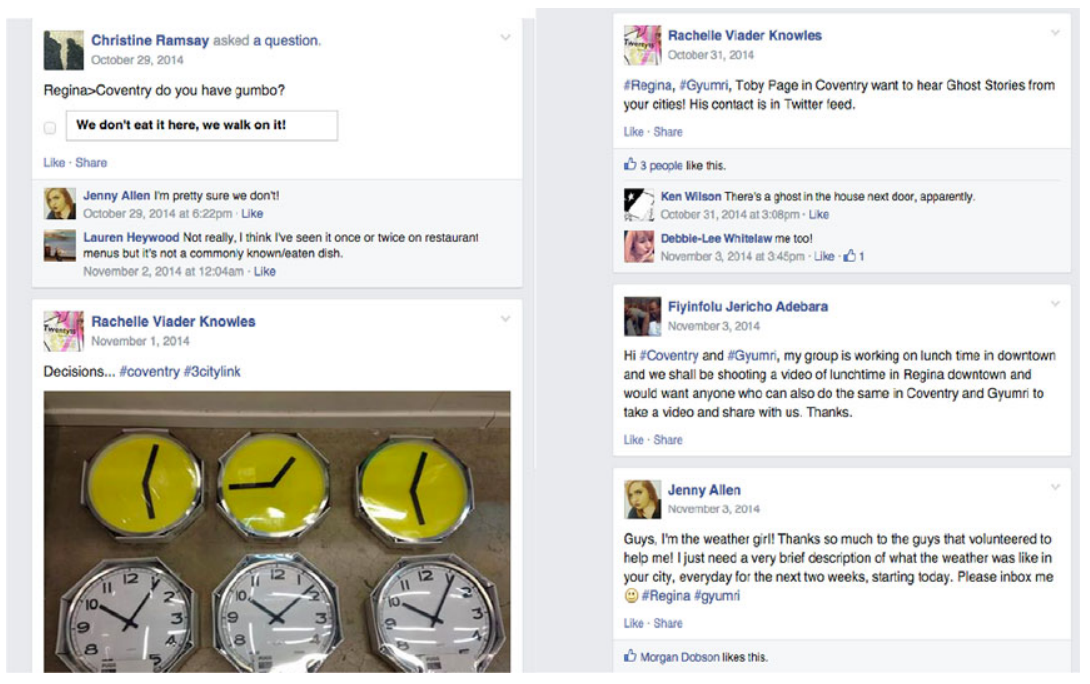

\section{Figure 3}

Enacting the translocal dialogue: 9:00am Regina is 3:00pm Coventry is 7:00pm Gyumri. Clockwise from top left: Excerpts from student Facebook discussion threads: the clocks in the Lanchester Gallery, Coventry 
and 'Next time I would involve myself more. I spent a lot of time avoiding meeting new people, and that was a loss' (Regina).

Being a student is to be in a state of anxiety, not only over assessment, feedback and workload pressures, but also self-doubts about personal ability, being able to contribute and coping with uncertainty (Barnett 2007). In sharing their ideas about the ways in which the project could be improved, suggestions ranged from the coursework being optional or not marked, to the project being even more experimental. It was also evident that students could see the benefits of using this type of open, connected learning with students from other countries as well as a wider public audience, as space and time to be more playful, to investigate, be open-minded, and not panic!

Advice to future students included: 'Don't be afraid to make contact with the overseas students; throw yourself into it. Experiment and think outside the box; let yourself get inspired. Get involved; push more' (Coventry); 'Don't gloss over the idea of translocal communication - it is the unexpressed point of the project; Embrace the cultural differences offered freely by collaborators abroad - anything strange is an opportunity to learn and broaden one's horizons' (Regina); and 'Engage with the project, start with your own strengths and interests and then relate them to the city and culture. Make requests! Put yourself in a position to be inspired by the unexpected! Fulfil requests. Make a list from the Skype call about your ideas and tackle all of them as it may inform your work' (Coventry).

In relation to the quality of the art produced, staff commented that there were high levels of praise for the work of students at all sites, and that the quality of work being produced was higher than would have been produced in a traditional fine art studio. It was suggested this was in response to the change in the learning context, the perceived value of students producing work for an exhibition, and the outward face of the gallery raising students' ambition.

\section{Discussion}

\#3CityLink relocated fine art pedagogy and introduced students to strategies that address social relations and communications in the context of transnational issues and concerns.

Nussbaum (1997) argues that education should be valued for its intrinsic tenets, which not only expand an individual's freedoms but also the opportunities they have to achieve.

Students need to be confronted with learning that seeks to challenge, provoke and evoke, so that they can (re) position themselves in relation to a theme or question, and honour the complexity of what is to be learnt. In \#3CityLink the level one students at Coventry University were not given the opportunity to become comfortable in a studio space but were (almost) immediately thrown into an unfamiliar, open space with second year students. The second year students were moved out of their familiar studio spaces and into a shared public space, with level one students. In Gyumri students had opportunity to work with local artists on live project work, and in Regina, the group of third year film production students, mostly used to working on film crews towards traditional single-channel outputs, were required to rethink their (limited) sense of the gallery as a space for the production of media work. Further, the interactivity of Skype, as a form of moving image, informed by current thinking in the field of 'expanded cinema', offered 
students opportunity to explore the explosion of the screen outward, 'toward immersive, interactive, and interconnected forms of culture' (Marchessault \& Lord 2007, 7; Youngblood 1970; Hatfield 2011). As Hatfield (2011, 12) writes, cinema is no longer 'yoked to the material conditions of a medium, and the cinematic experience can cross media boundaries ... involve intermedia, performance, spectacle, video, art and technology in addition to film, and be located within the "black box" of the theatre or the "white cube" of the gallery'.

From a social/cultural perspective knowledge, skills and attitudes are constructed through the social dynamics of learning rather than the internal cognitive processes. Vygotsky's $(1962,1978)$ work in this domain considers how learning is embedded within a social context and develops through social interaction with others, through learning relationships or communities of learning, with the learning context, and the relationship and interaction between the learner and the facilitator being of key importance (Kozulin et al. 2003). With the University of Regina film production students, the usual fixed production roles of 'director', 'actor' and editor' were no longer applicable in a context that required them to improvise and devise new roles, ways of working and collaborative attitudes. \#3CityLink impacted the students' developing learning about their art practice through the promotion of different peoples' cultural approaches to art, and the experience of students realising how one subject area could be 'explored through so many different ideas and forms of media' (Regina).

Scholarship on teaching and learning in higher education asserts that, whereas a lecture hall represents a style of teaching that is didactic and teacher / institution driven, learning spaces are different from teaching spaces and institutions need to reconfigure these spaces to incorporate new technology, facilitate formal and informal learning and enable interactions.

There is need, therefore, for programmes to keep up with practice that is constantly evolving and for course teams to consider approaches to digital pedagogy which adequately equip students to embrace uncertainty if graduates are to have a chance of being able to respond to the requirements of their future role. \#3CityLink prompted students to pursue and persist in new online learning spaces whilst also requiring them to take responsibility for organising their own learning and that of others through effective time management, and working to overcome obstacles, which arguably provided them with space to become more aware of their own learning process and needs (Dugdale 2009).

Students were prompted to examine what a 'finished' artwork can mean, and how partially completed pieces can also be illuminating, and that an installation could be a way to think about the process of doing art, rather than creating a piece of art as something static. In getting students to investigate alternative art forms and processes, the online events in the gallery became 'the work'.

Social media tools were seen to offer an effective space in which to develop asynchronous dialogue and discussion in support of the translocal project, but some students appeared reluctant to use these channels for engaging in learning, as confirmed by Dabbagh et al. (2012) and Kennedy et al. (2008). Students may be expert at using social media in their social networks, but they do not always translate this use to their formal or informal learning spaces without support. The importance of digital pedagogy then, is to enable students to engage in intellectual exchange, find one's voice, engender reflection, and be confronted in ways of working in the open. The idea of 'participatory culture' in art pedagogy is part of understanding some of the practices and social dynamics distinctive of a networked age 
(Jenkins et al. 2016). While learning through participation in distributed communities of interest and practice have multiplied, the opportunities for staff to develop valuable skills and attitudes by bringing these practices into formal education may also help students to rethink their learner role as active agents rather than passive recipients of information.

During the project, staff were asked to teach groups locally and translocally, using technology that they were not always comfortable with and in spaces that were not defined teaching spaces. In Coventry University, all fine art teaching shifted into the gallery space for the two-week live phase including contextual studies lectures that would normally take place in a lighting-controlled lecture theatre for an in-house audience only. The disruption therefore can be seen as both the move from the 'normal' teaching area to a gallery space, and the move towards a spatial integration of 'practice' (studio) and 'contextual studies' (lecture theatre). Staff feedback indicated that it was necessary to balance the risk associated with opening up the classroom through social media channels; this includes thinking about how exposing the work to others outside of the project may result in valuable contributions to the work in progress. Also, the benefits of increased exposure to the public relate to raising awareness and profiling the work and project by students and staff at the respective project sites.

\section{Limitations of the study and areas for development}

More preparation prior to the start of the live phase could have helped to create enhanced dialogue between the students and across the geographic borders. Online icebreaking sessions and small group collaborations could also have helped to break down the barriers and create more group interaction. From a review of the Facebook space, staff were directing and leading the discussions to a large extent, while students were often slow to respond and engage with each other. Whilst the team have no evidence of conversations that may have happened in personal spaces beyond what is reported by the students in the evaluation, there does not appear to have been effective communication outside the established spaces.

The audio-visual technology used to connect the three spaces suffered from poor sound at times and it was evident that attention was required in setting camera locations to best effect for virtual-visual exchange between the groups. The project also required staff to consider how they could apply and use the technology they already had within the department. As such, the implementation of a translocal project of this type requires adequate technology and familiarity with that technology on the part of the staff or their support team. During the project, the visual medium was felt to be useful, though not always used to its fullest potential. For future consideration, a roving camera or multiple cameras as well as additional microphones would be more effective to gain a fuller picture of each site's installation. Further, improving the quality of the visual 'presence' at other sites may improve the experience and engagement of students and virtual public audiences, at those sites.

\section{Conclusion}

\#3CityLink was about experimentation in learning which is willing to take risks. Working with and managing students' expectations, including how staff facilitate this type of learning, was informing in many ways, including how this approach to learning sits within the broader context of a course and educational culture. 
Disciplinary comfort zones were challenged within the group of researchers themselves, with practice-led and researchers from the social sciences bringing diverse and at times conflicting research methods to bear within the project. For the practitioners, the undertaking of \#3CityLink as a dialogue-based collaborative artwork constituted a method of research in and of itself, while for the researchers embedded in the project, this was the object of study, to be understood through methods drawn from the social sciences, namely interviews and descriptive case study. The reflexive consideration of methods of research in art and education is the extra-disciplinary work undertaken between the researchers, both through this project and in subsequent projects undertaken.

The quality of student work in the University of Regina and Gyumri Academy was higher than would have otherwise been produced, and in Regina University the expansion of student horizons into new territories and new ways of working through paradigms of expanded cinema was enabled. An issue raised here however, is the designation of 'student work' to a project that used the transformative potential of dialogue and the tactic of space-shift to explicitly disrupt traditional hierarchical relations between teachers and students. Nonetheless, using visual technology and social media for connected, artistic, critical co-investigation (including the staff hours involved), deserves further attention to explore visual 'presence' and its benefits in open education.

It is apparent that the international mobility of university students is still considered a desirable aspect of the internationalisation agenda in higher education. However, researching the subject learning students can experience, from projects such as \#3CityLink, continues to add weight to pedagogy focused on designing translocal learning opportunities, as part of 'internationalisation at home' initiatives. 'Think global, act local' (Equality Challenge Unit 2010) focuses on the potential of diverse, multicultural, multi-ethnic cities where students can benefit from the multicultural communities locally, which can provide fertile places for learning. The researchers engaged in this project continue to examine dialogues between the global and the local, and insights from \#3CityLink are serving to inform ongoing research and continued collaborations in this area.

Katherine Wimpenny is a Reader in Education Research in the Research Centre for Global Learning: Education and Attainment, at Coventry University, UK, where she works on a range of international and national projects focusing on methodological and pedagogical creativity, intercultural engagement and global education practices. Contact address: Research Centre for Global Learning: Education and Attainment, Coventry University, Coventry CV1 5FB, UK. Email: k.wimpenny@coventry.ac.uk

Rachelle Viader Knowles is an artist/academic and Associate Head (International) of the School of Art and Design at Coventry University, UK. Previously, Knowles served as Head of Visual Arts at the University of Regina in Saskatchewan, Canada from 2010 to 2014. Her research explores translocal approaches to dialogue as art and artistic practices/methods developed through participation, collaboration and networks. She holds a BA (Hons) in Interactive Art from the University of Wales, an MFA in Visual Arts (Multi Media) from the University of Windsor, Canada and she has recently completed a PhD at Plymouth University, UK. Contact address: School of Art and Design, Faculty of Arts \& Humanities, Coventry University, Coventry CV1 5DD, UK. Email: ab7307@coventry.ac.uk 
Christine Ramsay is Associate Professor in the Department of Film, University of Regina, Canada. Her research, teaching and service are in the areas of Canadian and Saskatchewan cinemas, masculinities in contemporary cinemas, curatorial studies in expanded cinema, the culture of small cities, and philosophies of identity. She currently serves on the editorial boards of Topia: Canadian Journal of Cultural Studies and Imaginations: Journal of Cross-Cultural Image Studies. She has published Atom Egoyan: Steenbeckett (Black Dog, 2017), Overlooking Saskatchewan: Minding the Gap (University of Regina Press, 2014) and Making It Like A Man: Canadian Masculinities in Practice (Wilfrid Laurier University Press, 2011) as well as chapters and articles in several anthologies and journals. Contact address: Department of Film, ED 243, University of Regina, Regina, SK, S4T 1V8, Canada. Email: Christine. Ramsay@uregina.ca

Jacqui Speculand is based in the School of Media and Performing Arts, Faculty of Arts and Humanities, Coventry University, UK, where she is a Senior Lecturer in Media Entrepreneurship. She has a Masters in IT and is currently studying for an EdDoc at Bournemouth University, UK. Her research explores learning environments and creative spaces that encourage and support an entrepreneurial approach to learning. Contact address: Faculty of Arts and Humanities, Coventry University, Coventry CV1 5DD, UK. Email: arx092@ coventry.ac.uk

\section{References}

Bauman, Z. (1998) Globalization: The Human Consequences. Cambridge: Polity Press.

Barnett, R. (2007) A Will to Learn: Being a Student in an Age of Uncertainty. Maidenhead: Society for Research into Higher Education / McGraw Hill.

Barnett, R. (2010) Lifewide education: a new and transformative concept for higher education?, in N. J. Jackson \& R. K. Law [Eds] Enabling a More Complete Education: Encouraging, Recognising and Valuing Lifewide Learning in Higher Education, pp. 23-35 (online). Available at: http://lifewidelea rningconference.pbworks.com/E-proceed ings (accessed 12 May 2017).

Bishop, C. (2012) Artificial Hells: Participatory Art and the Politics of Spectatorship. London: Verso.

Braun, V. \& Clarke, V. (2006) Using thematic analysis in psychology, Qualitative Research in Psychology, Vol. 3, No. 2, pp. 77101.

Dabbagh, N. \& Kitsantas, A. (2011) Personal learning environments, social media, and self-regulated learning: a natural formula for connecting formal and informal learning, The Internet and Higher Education, Vol. 15, No. 1, pp. 3-8.

Dugdale, S. (2009) Space strategies for the new learning landscape, Educause Review, Vol. 44, No. 2, pp. 51-62.

\section{Equality Challenge Unit (2010)}

Internationalisation and Equality and Diversity in Higher Education: Merging Identities (online). Available at: http:// www.ecu.ac.uk/wp-content/uploads/externa I/internationalisation-equality-diversity-inhe.pdf (accessed 8 November 2016).

Frayling, C. (1993/4) Research in Art and Design, Royal College Of Art Research Papers, Vol. 1, No. 1, pp. 1-5 (online). Available at: http://researchonline.rca.ac.uk/384/3/fra yling_research_in_art_and_design_1993.pdf (accessed 12 July 2012).

Gergen, K. J. (2003) Knowledge as socially constructed, in M. Gergen \& K. J. Gergen [Eds] Social Construction: A Reader. London: Sage, pp. 15-17. 
Hatfield, J. (2011) Expanded cinema: proto-, photo and post-photo cinema, in A. L. Rees et al. [Eds] Expanded Cinema: Art,

Performance, Film. London: Tate Publications, pp. 12-21.

Held, D., McGrew, A. \& Perraton, J. (1999) Global Transformations: Politics, Economics and Culture. Stanford, CA: Stanford University Press.

Jamieson, P., Fisher, K., Gilding, T., Taylor, P. \& Trevitt, A. (2000) Place and space in the design of new learning environments, Higher Education Research and Development, Vol. 19, No. 2, pp. 221-36.

Jenkins, H., Ito, M. \& Boyd, D. (2016) Participatory Culture in a Networked Era: A Conversation on Youth, Learning, Commerce, and Politics. Cambridge: Polity Press.

Kennedy, G., Judd, T., Churchward, A., Gray, K. \& Krause, K. (2008) First year students' experiences with technology: are they really digital natives?, Australasian Journal of Educational Technology, Vol. 24, No. 1, pp. 108-22.

Kozulin, A., Gindis, B., Ageyev, V. \& Miller, S. [Eds], (2003) Vygotsky's Educational Theory in Cultural Context. New York: Cambridge University Press.

Kwon, M. (2002) One Place After Another: Site Specific Art and Locational Identity. Cambridge, MA: MIT Press.

Marchessault, J. \& Lord, S. (2007) Introduction, Fluid Screens. Expanded Cinema. Toronto: University of Toronto Press, pp. 3-25.

McLoughlin, C. \& Lee, M. J. (2008) Future learning landscapes: transforming pedagogy through social software, Innovate: Journal of Online Education, Vol. 4, No. 5, article 1 (online). Available at: https://nsuworks. nova.edu/innovate/vol4/iss5/1 (accessed 8 November 2016).

Meet in the Middle: Stations of Migration and Memory between Art and Film (online), Regina (2014-2016). Available at: https://meetinthemiddle.squarespace.com. (accessed 8 November 2016).

Nussbaum, M. (1997) Cultivating Humanity: A Classic Defence of Reform in Liberal Education. Cambridge, MA: Harvard University Press.

Oblinger, D. (2006) Space as a Change Agent, in D. Oblinger [Ed.] Learning Spaces. Washington, DC: Educause (e-book). Available at: https://www.educause.edu/ research-and-publications/books/learningspaces/chapter-1-space-change-agent (accessed 19 August 2016).

Redden, E. (2014) Teaching with Tech Across Borders, Inside Higher Ed, 9 July (online). Available at: https://www. insidehighered.com/news/2014/07/ 09/faculty-use-internet-based-technologiescreate-global-learning-opportunities (accessed 12 May 2015).

Simons, H. (2009) Case Study Research in Practice. London: Sage.

Stake, E. R. (1995) The Art of Case Study Research. London: Sage.

Vygotsky, L. S. (1962) Thought and Language. Cambridge, MA: MIT Press.

Vygotsky, L. S. (1978) Mind in Society: The Development of Higher Psychological Processes. Cambridge, MA: Harvard University Press.

Youngblood, G. (1970) Expanded Cinema. New York: Dutton. 